\title{
THE FEMINIST AGENDA, A FALL OF HIERARCHAL REDRESS OR AN ATTEMPT TO ESTABLISHING AN 'EQUAL' SOCIETY GONE WRONG: AN INTERNAL CRITIQUE TO FEMINIST THEORIES*
}

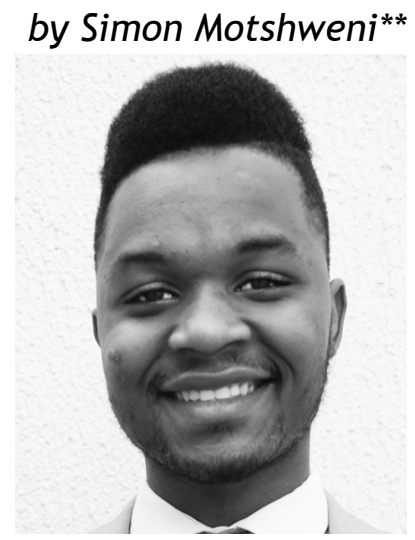

'To be fully subversive, the methodology of feminist legal theory should challenge not only law's content but its tendency to privilege the abstract and unitary voice and this gender essentialism also fails to do' ${ }^{1}$

* The aim of this paper is not to come to the defense of patriarchal systems of domination or perpetuate the subjugation of women in a male dominated legal order. I also acknowledge that as a man, I may not be 'best positioned' to talk about feminism as I do not have the lived experiences of the subjugation of women in society and feminists would argue that I 'enjoy' a position of an unwarranted privilege. However, I wish to make clear that the jurisprudential differences regarding the role and impact of feminist legal theories to the subject of law are a persistent 'conscious raising exercise' in legal philosophy and this paper merely aims to extend the existing literature on the subject of feminism in jurisprudential discourse. Nonetheless, Feminism is for Everyone, isn't it ...?

** Third year LL.B, University of Pretoria, 2019. I would like to thank Ms Zenia Pero for her critical engagement, advice, feedback and patience while I was writing this paper; Mpho Mogadime, Thato Maruapula and Franciscus Crouse for their feedback and review comments. All errors, omissions and shortcomings are undoubtedly my own.

1 A Harris 'Race and Essentialism in Feminist Legal Theory' (1990) 3 Stanford Law Review at 581. 


\section{Introduction}

The aim of this paper is to interrogate the post-1994 feminist approaches to jurisprudential discourse. This interrogation will include a consideration as to whether critical instead of 'traditional' feminist theories contribute in transforming or decolonising South African law and jurisprudence. It is my suggestion that the inquiry to address 'gender equality' before and without addressing issues of racism and racial classism simultaneously in South Africa contributes effectively to the continued marginalisation of black women. As such, my position attempts to engage with the critical feminist approaches in order to address the prejudices that traditional feminist approaches impose on black women.

The focal theoretical point of departure for this interrogation is critical race feminism. ${ }^{2}$ Critical race feminism proposes a progressive initiative for addressing the inconsistencies embodied within the traditional feminist approaches and is thus suitable for the South African post-apartheid context as it may trigger 'transformative possibilities'. ${ }^{3}$ It is my contention that in order to address the marginalisation of black women, the traditional feminist approaches (such as the dominant feminist approaches) must be done away with for they are a hindrance to legal reform, as they prejudice the very structure they claim to protect.

\section{The different types of distinctions between traditional and critical feminist approaches.}

This essay speaks of feminism in broad legal and philosophical terms. Scholars within the literature relating to feminist theories define feminism as a collection of approaches and ideologies aimed at defining, establishing and defending equal political, economic and social rights for women. ${ }^{4}$ The two general types of feminist approaches will be interrogated below.

\subsection{Traditional feminist approaches}

Traditional feminist approaches are identified as the dominant approaches to feminism. Their goal is primarily aimed at addressing the 'order of gender hierarchy where the female is excluded and

2 K Van Marle \& E Bonthuys 'Feminist theories and concepts' in C Albertyn \& E Bonthuys (eds) Gender, law and justice (2007) 32-37; AC Dailey 'Feminism's Return to Liberation' (1993) 102 The Yale Law Journal at 1274.

3 Y Jooste 'Contemplating a post-apartheid feminist jurisprudence' LLM Thesis, University of Pretoria, 2011 at 1.

$4 \quad$ M Davies 'Asking the law questions' (2008) 213. 
subordinate' to the other. ${ }^{5}$ Van Marle and Bonthuys in their chapter entitled 'Feminist, Theories and Concepts' aptly introduce the different kinds of traditional feminist approaches and these include liberal feminism, Marxist feminism, radical feminism and relational and cultural feminism. The authors argue that these traditional feminist approaches generally accept that society perceives masculine characteristics to be more superior to feminine characteristics. ${ }^{6}$

In particular, liberal feminists dispute that all women show feminist characteristics, and as such, they argue for the removal of gender bias from the law. ${ }^{7}$ The authors argue that liberal feminism places more emphasis on formal rather than substantive equality because the 'approach' only affords certain rights to limited women who share characteristics of the middle class men, to the exclusion of 'feminine' women, the working class of women as well as black women. ${ }^{8}$ Authors against this form of feminist approach argue that the concentration of feminism on the public roles of women does not alleviate the problems such women face in their domestic homes. ${ }^{9}$

On the other hand, Marxist feminism lays the foundation for socialist feminism. Marxist feminists argue that the notion of private property ownership is the root of the subjugation of women in society as private property is exclusive to a man's access. ${ }^{10}$ Socialist feminism adds on to this by pointing out that women are oppressed as a result of patriarchy and the class system. The feminists argue that these systems use sexuality, identity and class to suppress women. ${ }^{11}$

Furthermore, radical feminism perceives the oppression of women as the most fundamental form of oppression, it posits in this instance, that sisterhood transcends barriers of race, class, and culture. $^{12}$ This view will be critically interrogated in this essay. In addition, relational or cultural feminism accept the 'sexualisation of oppositional pairs but reject the hierarchisation', as they accept that women can be defined in terms of their relationships to others but view these relationships as sources of strength and not necessarily ways of encouraging systematic oppression. ${ }^{13}$

Jooste (n 3) 13.

Van Marle \& Bonthuys (n 2) 32.

Van Marle \& Bonthuys (n 2) 33.

8 C MacKinnon 'Difference and dominance: On sex discrimination in Bartlett \& Kennedy' (1993) 102 The Yale Law Journal at 81-85.

9 L Benería \& G Sen 'Class and gender inequalities and women's role in economic development: Theoretical and practical implications' (1982) 8 Feminist Studies at 164-172.

10 Van Marle (n 2) 33.

11 Van Marle (n 2) 33-34.

12 Van Marle (n 2) 35.

13 Van Marle (n 2) 35-36. 
Thus, I detect from the authors' literature that traditional feminist theories turn a blind eye on race and racial classism, which would hierarchise white women above black women and thereby create a system of inequality within the sisterhood umbrella of feminism. ${ }^{14}$ Therefore, traditional feminism fails to conceive the prospect of the need for racial reconciliation and equality between white women and women of colour. Historically, the role of traditional feminist theories was [and still is] to disrupt the gender based hierarchy which places women on the pedestal, subordinate to a masculine and male dominated order. ${ }^{15}$ However, I submit that traditional feminist approaches do not provide a solution for the post1994 South African context and there is need to serve justice to black South African women who have suffered the 'dual-oppression' of both black and white men as well as that of white women.

It is against this background that I strongly recommend South Africa resorts to critical feminist approaches which introduce the fact that the gender subordination of black women does not equate to that of white women and that 'traditional feminist theories do not pay sufficient attention to the racialised experiences of black women'. ${ }^{16}$

\subsection{Critical feminist approaches}

Van Marle and Bonthuys as well as bell hooks introduce critical race feminism, a school of thought which emanates from Critical Race Theory. They argue that critical race feminists criticise traditional feminist theories on four bases:

... it excluded experiences of black women, the issues deemed important are those relevant to white feminist, a shared experience of sisterhood and lastly the alienation of black women and working class women. ${ }^{17}$

Thus, when resorting to critical theories to feminism, matters affecting black women are concurrently addressed within race, class and gender. ${ }^{18}$ On the other hand, classist feminism also recognises the class struggles endured by different women in society. ${ }^{19}$ Simply put, it tells us that the power wanted by white women, was the same they had perceived their men enjoying and that the economic and political privilege enjoyed by white working-class women can never be said to

14 B Hooks Feminism is for everybody: Passionate Politics (2000) 13 \& 55. See also Van Marle (n 2) 32-37; S Liebenberg 'Needs, rights and transformation: adjudicating social rights' (2005) Paper 8 Centre for Human Rights and Global Justice 3.

15 Jooste (n 3) 22.

16 Van Marle (n 2) 40.

17 Van Marle (n 2) 40.

$18 \mathrm{~K}$ Crenshaw 'Mapping the margins: Intersectionality, identity politics and violence against women of colour' in K Crenshaw, N Gotanda, G Peller \& K Thomas (eds) Critical race theory: The key writings that formed the movement (1996) 357. 
be the same for other women in general. This is given further context by critical race feminism, which critically asserts and acknowledges that white women and black women are not in the same hierarchical level, and therefore, black women must fight a battle of 'white supremacy' in this sisterhood umbrella before they fight systems of patriarchy. ${ }^{20}$

\subsection{Distinctions between traditional and critical feminist approaches}

From a review of the literature, one can conclude that the major difference between the traditional and critical feminist approaches is the level of intersection between race, class, gender and sexuality in each approach. ${ }^{21}$ Traditional feminist approaches are primarily focused on the unequal treatment between men and women in general, without copiously intersecting the inequalities existing between women as a result of racial classism. ${ }^{22}$ Such a colour-blind approach does not offer South Africa any possibility for legal transformation or decolonisation because the subject of law would still remain unchanged. ${ }^{23}$ Critical feminism on the other hand, intertwines the subject of race and gender whilst pursuing feminism. ${ }^{24}$ Unlike traditional feminism, critical feminism suggests that the overarching problem for 'equality' in society is not one that can be resolved by merely disrupting heteronormativity and patriarchy, but also unveiling these heteronormative and patriarchal characteristics within the context of race. ${ }^{25}$

Crenshaw argues, that critical feminist theories transcend traditional feminist theories because they not only focus of the subject of gender, but also, the subject of race. ${ }^{26}$ She posits, that ignoring differences (such as racial classism) within groups frustrates the very goal towards equality by traditional feminist approaches. 27 Crenshaw illustrates that many of the experiences women of colour face are not considered within the traditional margins of either race or gender discrimination because the intersection of race and gender

$20 \mathrm{~K}$ Crenshaw 'Demarginalizing the intersection of race and sex: A black feminist critique of antidiscrimination doctrine, feminist theory and antiracist politics' in J James \& TD Sharpley-Whiting (ed) The Black Feminist Reader (2000) 218.

21 M Lugones 'The coloniality of gender' in M Lugones (ed) The Palgrave Handbook of Gender and Development (2016) 1.

22 C Albertyn \& B Goldblatt 'Facing the challenge of transformation: Difficulties in the development of an indigenous jurisprudence of equality' (1998) 14 South African Journal of Human Rights at 251.

23 DA Davis \& S Wildman 'The legacy of doubt: Treatment of sex and race in the HillThomas Hearings' in AK Wing (ed) Critical Race Feminism a Reader (1997) at 175.

24 Crenshaw (n 18) 357.

25 S Jackson 'Why a materialist feminism is (still) possible and necessary' (2001) 24 Women's Studies International Forum at 283.

26 Crenshaw (n 18) 357.

27 Crenshaw (n 18) 357. 
'factors into black women's lives in ways that cannot be captured wholly by looking at the women race or gender dimensions of those experiences separately'.28

It is against this backdrop that I detect whether critical feminist approaches would offer any prospects towards transformation or decolonisation in the subject of jurisprudence and the law in a post1994 South African context. I shall now resort to ponder upon and develop the meaning of transformation and decolonisation within the context of legal philosophy in post-1994 South Africa.

\subsubsection{Transformation}

Cornell defines transformation as "change radical enough to so dramatically restructure any system - be it is political, legal, or social - that the identity of the system is itself altered'. ${ }^{29}$ Similarly, the Education White Paper 3 provides that transformation '... requires that all existing practices, institutions and values are viewed anew and rethought in terms of their fitness for the new era'. 30

Transformation is based on the need to change South Africa into a democratic state grounded on human dignity, equality and freedom. ${ }^{31}$ Focal to the issue of transformation is the realisation of social justice and socio-economic equality across all races and genders because the Constitution mandates transformation that results in substantive equality and not some mere 'formal' change. ${ }^{32}$ Van Marle therefore contends, that an interpretation that aims to achieve transformative constitutionalism is necessary as it would engage deeply with the pre and post-1994 South African contexts in adjudication and aim towards achieving a substantive change of the status quo in which black South African women find themselves. ${ }^{33}$ Here, she suggests that in order to transform as a society, we need to advocate for critical theories of law and follow a critical approach to transformative adjudication by accepting and acknowledging canons of indeterminacy of the law. ${ }^{34}$ After all;

Law is simply politics dressed up in a different garb, it neither operates in a historical vacuum nor does it exist independently of ideological

28 Crenshaw (n 18) 358.

29 FM Githuru 'Transformative constitutionalism, legal culture and the judiciary under the 2010 Constitution of Kenya' LLD thesis, University of Pretoria, 2015 at 91.

30 RJ Trunette 'Decolonising the Curriculum, transforming the University: A discursive perspective' DUT 4. 03 March 2017 https://www.dut.ac.za/wpcontent/uploads/2017/03/T-JOSEPH.pdf (accessed 27 May 2019).

31 Githuru (n 29) 174

$32 M$ Wesson \& $M$ Du Plessis 'Fifteen years on: central issues relating to the transformation of the South African judiciary' (2008) 24 SAJHR at 200.

33 Wesson \& Du Plessis (n 32) 191.

34 D Dyzenhaus 'Law as a justification; Etienne Mureinik's conception of legal culture' (1998) 14 SAJHR at 29. 
struggles in society. Legal doctrine not only does not, but also cannot, generate determinate results in concrete cases... legal doctrine can be manipulated to justify an almost infinite spectrum of possible outcomes. ${ }^{35}$

Critical feminist theories offer transformative possibilities to the law to integrate an appreciation of the intersection of race and gender realities. ${ }^{36}$ This can be done through legal processes of altering substantive law to retort to black women's needs. ${ }^{37}$ It is on this note that it must be made clear, that critical feminist theories find their roots in Critical Legal Studies (CLS), which places specific focus on history to find answers to current transformation issues in South Africa. ${ }^{38}$ Adherents of the CLS place indeterminacy as being central to the law and legal rules. ${ }^{39}$ This gap of 'indeterminacy' of the law means that legal norms are not capable of a 'stable and preordained meaning'. 40 This further entails that judges have to give meaning to legal norms and provisions because laws themselves cannot determine the meaning of their own provisions. It is against this reality that the courts should lean on critical feminist theories when addressing issues affecting black women, in order to bring about transformation in the law and jurisprudence. This kind of approach taken by the courts would be reflective of Klare's interpretation of transformative constitutionalism, which requires judges to adjudicate by using not only novel legal norms of this constitutional egalitarianism but even more so, new adjudicative methods as required by our new legal paradigm. ${ }^{41}$

To my mind, this way of applying the law will change the way in which the law is taught as a subject in legal education as it would mark a shift from the 'law teacher' teaching the law in a conservative and determinate way, to teaching the law 'in a manner that [seeks] to prepare students for critical application of legal doctrines'. 42 This requires law teachers to stop teaching law as a coherent body of legal norms but present the law with its fragmented, pluralist, inconsistent and habitually contradictory prerogatives to authority that accumulatively make the subject of law. ${ }^{43}$ In my view, this means, when teaching Feminist Jurisprudence as a subject of law,

35 A Hutchinson \& P Monahan 'Law, politics and critical legal scholars: the unfolding drama of American legal thought' (1984) Stanford Law Review at 206.

36 Crenshaw (n 18) 371. See also N Giffney 'Introduction: The ' $q$ ' word' in N Giffney (ed) The Ashgate Companion to Queer Theory (2009) 1 -13.

37 Crenshaw (n 18) 371.

38 WB le Roux \& K van Marle 'Critical legal studies' in C Roederer \& D Moellendorf (eds) Jurisprudence (2004) 246-247.

39 D Kennedy 'Form and substance in private law adjudication' (1976) 89 Harvard Law Review at 1685.

40 As above.

41 G Quinot 'Transformative legal education' (2011) Stellenbosch Law Review at 6.

42 T Madlingozi 'Legal academics and progressive politics in South Africa: Moving beyond the ivory tower' (2006) Pulp Fictions at 17

43 Quinot (n 41) 8. 
elaboration must not only be placed on the centralised gender theme, but the different categories that persist within the gender itself (such as race and class). By espousing this kind of pedagogy, we shall have the ability to imbue a transformed subject of law as instructed by our Constitution. ${ }^{44}$ It is based on this trail of thought that I believe that such transformation in legal education would lead to its decolonisation thereof.

Essentially, the Constitution seeks to achieve substantive equality through transformative constitutionalism which seeks to cater for and resolve societal and economic disparities, inequality and matters of subordination which may exist in society. ${ }^{45}$ Thus, to achieve this substantive equality, Westen tells us that:

the law is required to take into account the varied circumstances of individuals which need special attention to ensure a favourable outcome to all. The Constitutional Court emphasized this in National Coalition for Gay and Lesbian Equality \& Another $v$ Minister of Justice \& others. ${ }^{46}$ It stated that the idea of substantive equality takes into account the social and economic conditions of individuals and historically disadvantaged groups in society, and that even though we are each different, unique, and with various talents, law in the Constitution ought to be utilized to mitigate the adverse effects of such inherent differences. This is opposed to formal equality which simply connotes sameness, equal, or similar treatment of all people. It requires the law to treat people in the same manner irrespective of circumstances that they may find themselves in. ${ }^{47}$

\subsubsection{Decolonisation}

There is a rich pool of definitions regarding decolonisation in literature review. Scholars such as Le Grange contend that decolonisation is a response to the first and second generation of colonialism, the first being that of colonising by conquering physical spaces and individuals, the second being the colonisation of the mind through disciplines such as education and law. ${ }^{48}$

The transformation spoken of above, will lead to a process of decoloniality in the law and jurisprudence. I must admit, that the process of decoloniality will not be achieved overnight as 'it will be a protracted struggle'. ${ }^{49}$ Trunette in particular, posits that this is because the majority of academic staff in South African Universities are not prepared to initiate a decoloniality transformation process as

44 As above.

45 P Langa 'Transformative constitutionalism' (2008) Stellenbosch LR at 351.

46 National Coalition for Gay and Lesbian Equality \& Another v Minister of Justice \& others 1999 (1) SA 6 (CC) [60] to [62].

47 P Westen 'The empty idea of equality' (1982) Harvard Law Review at 555-596.

48 Trunette (n 30) 6.

49 As above. 
they themselves are products of coloniality. ${ }^{50}$ Thus, in as much as we live in a 'postcolonial' South Africa, the law and jurisprudence are still colonised. Such 'post-coloniality' is presented by virtue of the fact that colonial administrations have been eliminated from government structures. ${ }^{51}$ It is against this background that colonial forms of domination such as traditional feminist approaches which cater (almost exclusively) for the needs of white women continue even after the end of colonial administrations. ${ }^{52}$ It is through applying CLS that issues of coloniality and transformation can be effectively addressed. 53

Literature reveals, that traditional feminist approaches have been criticised for ignoring women from minority groups who have their own separate and special experiences. ${ }^{54}$ Thus, it must not be ignored that it may be argued by traditional feminists that, given the South African context where black women form the majority of the female population and specifically outnumber white women, critical feminism is not relevant because black women's struggles are not silenced in the hands of the majority's race. ${ }^{55}$ They may argue, that the critical approach to feminism focuses on race at the expense of the equality of sexes. ${ }^{56}$ However, it is important to contextualise the present time with the South African history in which blacks and whites existed in hierarchical levels, with the white person seen as superior, and the black person seen as inferior. It is my contention that in fact, this incongruous view particularly still exists in South Africa. It is in light of this that we must understand that critical feminism works to address the intersectionality of race and gender simultaneously, even if race is rightfully placed at the centre of the paradigm. ${ }^{57}$

Therefore, I advocate for the application of CLS which provides us with useful theoretical constructs for transformation and decoloniality, by explaining how traditional approaches to social concepts not only perpetuate colonialism, but also maintain racism and Eurocentric epistemologies. ${ }^{58}$ It is against this backdrop that I posit that race as a social construct has not been sufficiently dealt with in post-apartheid South Africa and our generation should work to rectify this omission. Trunette makes clear that 'race is a social construct matter and as such, cannot be swept under the rug when

50 Trunette (n 30) 6. See also K Wiredu 'Conceptual decolonization as an imperative in contemporary African philosophy’ (2002) 35 Rue Descartes at 53-64.

51 Trunette (n 30) 7.

52 As above.

53 Trunette (n 30) 8.

54 B Smith 'Intersectional discrimination and substantive equality: A comparative and theoretical perspective' (2016) 16 The Equal Rights Review at 73.

55 Hooks (n 14) 13.

56 Hooks (n 14) 55.

57 Trunette (n 30) 11.

58 Trunette (n 30) 10. 
theorising about gender injustices'. ${ }^{59}$ It is critical theories that can serve as the way through which black womens' subaltern voices are heard by focusing on the intersectionality between race, gender and classism. ${ }^{60}$ Critical feminism challenges whiteness as a norm and those who claim that traditional feminism is 'neutral and objective'. ${ }^{61}$ Transformation and decolonisation of the law and jurisprudence challenge exactly this claim of neutrality, objectivity and colour-blindness to white privilege. ${ }^{62}$

As aforementioned, introducing a critical way of thinking about the law and jurisprudence will eventually lead to changes in terms of which the law is taught in legal education. It is perhaps plausible to assume that this change would thus lead to decolonising legal education itself. The decolonisation of legal education entails initially decolonising the curriculum and subsequently, the university and the higher education landscape. ${ }^{63}$

\section{What effect does the traditional feminist approach have on the constitutional imperative to equality, and what impact does it have on the philosophy of jurisprudence and its transformation thereof?}

Traditional feminist approaches encumber the constitutional imperative to substantive equality because it is primarily aimed at a formalistic kind of equality. ${ }^{64}$ It does not allow for transformation to occur and thus restricts the decolonisation of jurisprudence and the law in general. ${ }^{65}$ To illustrate how 'ineffective' traditional approaches are to the discourse of transformation and decolonisation, I will journey into a discussion that shows that traditional approaches such as restricted jurisprudence in particular, burden the discourse on transformation and decolonisation, whereas general jurisprudence presents us with the possibilities of transforming and decolonising the study of law and jurisprudence. ${ }^{66}$

59 As above.

60 Crenshaw (n 18) 357 - 371.

61 C Douzinas \& A Geary Critical jurisprudence: The political philosophy of justice (2005) 259.

62 P Nyawo 'A critical race feminist perspective on section 217 of the Constitution' LLM Thesis, University of Pretoria, 2013 at 37.

63 Trunette (n 30) 11.

64 KE Klare 'Legal culture and transformative constitutionalism' (1998) 14 SAJHR at 146.

65 Githuru (n 29) 23.

66 As above. 
For purposes of this illustration, restricted jurisprudence must be seen as traditional feminism and general jurisprudence must be seen as critical feminism. Restricted jurisprudence follows a dominated approach of thinking focusing on a restricted way of defining and delimiting what properly construes 'pure' law and distinguishing it with other disciplines. ${ }^{67}$ Here, the act of determining what the law is, is aimed at restricting what lawyers can do and look at. ${ }^{68}$ This results in the deterioration of the discipline of law because it limits the application of the law as the law becomes 'a science with predetermined formulas'. ${ }^{69}$ In other words, a mere study of legal norms with no critical understanding and engagement between the law and the social context in which it applies. ${ }^{70}$ The law is applied in a narrow way which is detached from historical context and societal implications. Similarly, traditional feminism follows a narrow approach of thinking restricted to the central theme of gender, without any considerations of historical context and issues of race and classism.

On the other hand, general jurisprudence can be explained as returning to the classical inquiry of jurisprudential philosophy. ${ }^{71}$ Adopting a broader meaning of what 'law' entails, while examining 'legal aspects of social reproduction both within and without state of law'. ${ }^{72}$ This means that general jurisprudence takes into account all aspects that make a societal structure including politics, philosophy, economics as well as emotional and physical modes of production and reproduction. ${ }^{73}$ General jurisprudence is the legal interzone which concerns itself with intersectional issues between legal texts and the social world. ${ }^{74}$ Similarly, critical feminism can be regarded as the legal interzone that places focus of the intersectionality between race, gender and classism. ${ }^{75}$ It is based on this trail of thought that one can perceive that a general and critical way of thinking may promote possibilities of transformation and decolonisation in legal philosophy, in particular, the law and jurisprudence.

When following general jurisprudence, the way in which the law is taught is not limited to teaching it in the colonial language of English. ${ }^{76}$ General jurisprudence allows us to use the law in order to transcend coloniality. This can be done by reassuring the use of indigenous dialects in academic contexts while correspondingly

67 Douzinas \& Geary (n 61) 6.

68 Douzinas \& Geary (n 61) 259.

69 Douzinas \& Geary (n 61) 6

70 Douzinas \& Geary (n 61) 259 J Murungi An introduction to African legal philosophy (2013) 32.

71 Douzinas \& Geary (n 61) 10.

72 Douzinas \& Geary (n 61) 11.

73 As above.

74 Douzinas \& Geary (n 61) 12.

75 Crenshaw (n 18) 360.

76 Douzinas \& Geary (n 61)259. 
enhancing multilingualism. Since societal implications are taken into account here, this encourages the law not to be applied in a vacuum but with proper considerations of its impact on society - thus making the law 'fluid' and indeterminate. This indeterminacy offers the law the prospect to be applied in favour of transformation and decolonisation. ${ }^{77}$ My argument here is that, in order to capitalise on the possibility of transformation and decolonisation, the law must be read and interpreted in a critical way. In addition, this would be in line with the concept of transformative constitutionalism. Van Marle posits, that to term something transformative means to advocate a disruption in the traditional connection with law in solitude and traverse other disciplines. ${ }^{78}$ A major purpose of transformative constitutionalism continues to be the need for change and the healing of wounds and divisions of the past [and recurring] injustices in South Africa. ${ }^{79}$ Notably, one of the largest challenges towards transformation in South Africa remains the racial differences which effectively contribute towards the creation of social and economic gaps. $^{80}$

Klare notes that in South Africa, we are challenged and limited by a conservative approach to legal culture and this kind of approach is resistant to change and is largely formalistic thus, obscuring the attainment of social justice and substantive equality under the law. ${ }^{81}$ In order to attain substantive legal change and to overcome these limitations of legal norms, the law must mature away from the formalistic approach (traditional feminist approaches), it must be capable of breaking down the walls of this formalistic and conservative legal approach when circumstances so demand and necessitate. ${ }^{82}$

\section{How to resolve the conflict between race and gender struggles of black women?}

In a post-1994 South African context, issues of feminism cannot be addressed by solely placing focus on gender but the intersectionality between inter alia, race, gender, classism, must also be looked at. Thus, perhaps to reconcile the conflict of black womens' struggle of race and gender, it is plausible to lean on critical feminism which addresses both the issue of race and gender simultaneously. ${ }^{83}$ This is

Kennedy (n 39) 1685.

Githuru (n 29) 19.

Githuru (n 29) 3.

Githuru (n 29) 17.

Klare (n 64) 150.

Langa (n 45) 357-358.

Crenshaw (n 18) 360; D Bell 'Who's afraid of critical race theory' (1995) 4 University of Illinois Law Review 893 - 910. 
primarily because reliance on traditional feminism would not sufficiently and effectively address the prejudices faced by black women in society. ${ }^{84}$ As such, it is my suggestion that this 'sisterhoodfeminism' umbrella finds dysfunctionality in a society like South Africa, where the reality of racism still systematically exists and black and white women cannot be said to have the same 'women' struggles. 85

I am of the opinion that critical feminism is indeed the unattended call to which South Africa needs to answer, in order to address challenges it faces in respect of women and their position in society. I do not favour the traditional feminist approach because it does not address the idea of the inescapable and inherent racism in our 'postapartheid' South African context. ${ }^{86}$ I believe that a person's perception and experience of the world is indispensably determined by their life experiences, one of these being their position in the race structure of a society. Thus, an approach which has focal attention on both race and gender 'kills two birds with one stone', by addressing both issues of racial classism as well as gender equality. ${ }^{87}$

Furthermore, I posit that generally, in order to achieve this reconciliation, transformation must be capable of providing a persistent platform open to discussion and the changing demands of society as aptly captured by Langa when he says:

transformation is not a temporary phenomenon that ends when we all have equal access to resources and basic services and when lawyers and judges embrace a culture of justification ... permanent idea l... in which change is unpredictable but the idea of change is constant... sees the Constitution as not transformative because of its peculiar historical position or its particular socio-economic goals but because it envisions a society that will always be open to change and contestation, a society that will always be defined by transformation ... ${ }^{88}$

I submit, that in view of the fact that South Africa has not recovered and is still crippled by the unfinished and unsettled business of a colonial apartheid past, critical approaches to the law and jurisprudence in general, may provide reform to the current social and economic impasse. It is without doubt that in order to realise and achieve this reconciliation, transformation and decolonisation, we are required to engage with CLS on the subject of legal culture, education and philosophy. ${ }^{89}$ 


\section{Conclusion}

In this paper I have interrogated the post-apartheid feminist approaches to jurisprudential discourse by considering whether critical feminist approaches contribute in transforming or decolonising South African law and jurisprudence. I conclusively suggest that the inquiry to address 'gender equality' before and without addressing issues of racism and racial classism simultaneously in South Africa contributes effectively to the continued marginalisation of black women. As such, my position attempts to encourage that we engage with the critical feminist approaches in order to address the prejudices that traditional feminist approaches have on black women and to enhance possibilities of transforming and decolonising the law and jurisprudence in South Africa. 